\title{
Effect of simvastatin on burn-induced alterations in tissue specific glucose metabolism: Implications for burn associated insulin resistance
}

\author{
ALI A. BONAB ${ }^{2,4,5}$, EDWARD A.CARTER ${ }^{1,4,5}$, KASIE PAUL $^{5}$, MASAO KANEKI ${ }^{3,4,5}$, \\ YONG-MING YU ${ }^{1,4,5}$, RONALD G. TOMPKINS ${ }^{1,4,5}$ and ALAN J. FISCHMAN ${ }^{4,5}$
}

\begin{abstract}
Departments of ${ }^{1}$ Surgery; ${ }^{2}$ Nuclear Medicine; ${ }^{3}$ Anesthesia, Massachusetts General Hospital, Harvard Medical School, Boston, MA; ${ }^{4}$ Harvard Medical School, Boston; ${ }^{5}$ Shriners Hospitals for Children, Boston, MA, USA
\end{abstract}

Received April 22,2010; Accepted May 26, 2010

DOI: $10.3892 /$ ijmm_00000467

\begin{abstract}
In addition to their primary role in lowering plasma cholesterol, statins have a variety of other actions. We studied the effect of simvastatin treatment on burn injuryinduced changes in regional glucose metabolism. Groups of six CD-1 mice (male, $\sim 25 \mathrm{~g}$ ) were subjected to full thickness $30 \%$ total body surface area (TBSA) burn injury. The animals were treated with simvastatin at various doses $(0.02$, 0.2 and $2.0 \mu \mathrm{g} / \mathrm{kg}$, i.p.) for seven days. The following morning, mice were injected with ${ }^{18} \mathrm{~F}$ labeled 2-fluoro-2-deoxy-Dglucose $\left({ }^{18} \mathrm{FDG}\right)(50 \mu \mathrm{Ci})$ via the tail vein. Approximately 60 min after tracer injection, the animals were sacrificed and biodistribution was measured. A sub-set of burned mice with and without statin treatment and sham controls was injected with $\sim 1.0 \mathrm{mCi}$ of FDG and tracer distribution was evaluated by $\mu$ PET. In addition, oral glucose tolerance tests (OGTT) were performed in other groups of burned mice with and without statin treatment and sham controls. In the heart and brown adipose tissue (BAT), burn injury produced a highly significant increase in ${ }^{18} \mathrm{FDG}$ accumulation $(\mathrm{p}<0.01)$, whereas tracer accumulation in brain was markedly reduced $(\mathrm{p}<0.01)$. In the heart and BAT, simvastatin treatment produced dosedependent reductions in ${ }^{18} \mathrm{FDG}$ accumulation. In contrast, simvastatin did not affect ${ }^{18} \mathrm{FDG}$ accumulation in the brain. There was no effect of simvastatin treatment on ${ }^{18} \mathrm{FDG}$ accumulation in the heart, BAT or brain of sham-treated mice. Less pronounced effects were detected in other tissues that were studied. All animals had normal plasma glucose levels $(\sim 90 \mathrm{mg} / \mathrm{dl})$. The OGTTs demonstrated insulin resistance in burn injured mice which was reversed by statin treatment. Our results indicate that simvastatin reverses burn-induced increases in ${ }^{18} \mathrm{FDG}$ accumulation by the heart and BAT in a dose-dependent manner but does not affect burn-induced reductions of ${ }^{18} \mathrm{FDG}$ accumulation by the brain. These findings
\end{abstract}

Correspondence to: Dr Alan J. Fischman, Shriners Hospitals for Children, 51 Blossom Street, Boston, MA 02114, USA

E-mail: aajjff@gmail.com

Key words: burn, glucose, ${ }^{18} \mathrm{~F}$ labeled 2-fluoro-2-deoxy-D-glucose, insulin resistance, brown adipose tissue, simvastatin, sepsis suggest that statins exert some of their effects by tissue specific modulation of glucose metabolism.

\section{Introduction}

Over the past several years, we have performed numerous studies of whole body and organ glucose metabolism with ${ }^{18} \mathrm{~F}$ labeled 2-fluoro-2-deoxy-D-glucose $\left({ }^{18} \mathrm{FDG}\right)$ in rodent models (mice and rats) of burn injury. Among the most common and striking findings of these studies, were alterations of glucose metabolism in the brain and heart (1-5). In the case of the brain, these studies demonstrated a consistent and marked reduction in ${ }^{18} \mathrm{FDG}$ uptake throughout the brain. Since burn injury is associated with insulin resistance and hyperglycemia, this finding could, at least in part, be due to competition of endogenous glucose with ${ }^{18} \mathrm{FDG}$ for brain uptake. However, when the raw uptake data from these studies were corrected for glucose levels, the finding of reduced central nervous system (CNS) metabolism persisted. These results are surprising, since glucose is the primary substrate for CNS energy metabolism and CNS uptake of glucose is maintained in most pathophysiological states.

In contrast to the brain, ${ }^{18} \mathrm{FDG}$ uptake in the myocardium was markedly increased after burn injury. When myocardial uptake of ${ }^{18} \mathrm{FDG}$ was corrected for the existing hyperglycemia associated with burn injury, the effect of the burn injury became even more profound. Clearly, these alterations in glucose metabolism in the brain and heart could be contributing factors in the increase mortality of septic animals with or without burn injury.

In addition to their primary role in lowering plasma cholesterol, statins have a variety of other actions. Statin pretreatment has been shown to protect mice against sepsis-related death (6) and this protection appears to be associated in part, with an attenuation of pro-inflammatory cytokine production, specifically IL-6 and TNF. Dobesh et al (7) demonstrated that use of statins in patients prior to the development of severe sepsis appears to produce a significant reduction in mortality compared with patients that were not receiving statins. In addition, it has been reported by Fogerty et al that treatment with statins prior to injury significantly decreased mortality and showed a trend toward reduced septic shock in 
a retrospective study of 223 elderly burn patients (8). Recently, we demonstrated that mortality produced by sepsis in mice with burn injury or by lipopolysaccharide challenge is greatly attenuated by simvastatin treatment $(9,10)$. However, the effects of statin treatment on the metabolic derangements and insulin resistance after burn injury or sepsis are unknown. In the present investigation, we studied the effect of simvastatin treatment on burn injury induced changes in regional glucose metabolism.

\section{Materials and methods}

Burn injury model. Male CD-1 mice weighing 25-28 g were purchased from Charles River Breeding Laboratories, Boston, MA. Full-thickness, non-lethal thermal injury [30\% total body surface area (TBSA)] was produced, as described previously (11) using a protocol approved by the Subcommittee on Research Animal Care of the Massachusetts General Hospital. Briefly, mice were anesthetized with ether and their backs were shaved with animal hair clippers. Under ether anesthesia, they were placed in molds exposing 30\% TBSA followed by emersion of the exposed area in a water bath at $90^{\circ} \mathrm{C}$ for $9 \mathrm{sec}$. The animals were immediately resuscitated with saline $(15 \mathrm{ml} / \mathrm{kg})$ by intraperitoneal injection. Sham control animals were treated similarly, except immersion was in room temperature water. After the procedures, the animals were caged individually and food and water were provided ab libitum.

Measurement of ${ }^{18} \mathrm{FDG}$ uptake in tissues of mice with burn injury. In preliminary studies, groups of six animals with burn injury were fasted overnight before tracer injection. The following morning, mice were injected with ${ }^{18} \mathrm{FDG}(50 \mu \mathrm{Ci})$ via the tail vein. Approximately $60 \mathrm{~min}$ after tracer injection, animals were sacrificed by cervical dislocation and complete biodistribution was measured. Radioactivity in aliquots of the injected was measured in parallel with tissue samples and results were calculated as the percentage of the injected dose per gram wet weight of tissue (\% ID/g). All results were expressed as means \pm SEM. Blood glucose levels were measured with a Contour glucometer (Bayer Inc.).

Effect of simvastatin treatment on regional glucose metabolism. Simvastatin (Merck Biosciences, Inc.) was dissolved in ethanol at a concentration of $10 \mathrm{mg} / \mathrm{ml}$ and diluted with normal saline to yield a final concentration of $10 \mu \mathrm{g} / \mathrm{ml}$. The placebo contained only ethanol in saline. The mice were injected with simvastatin i.p. for seven days at doses of 0 (placebo), 0.02 , 0.2 and $2.0 \mu \mathrm{g} / \mathrm{kg}$.

On day seven after burn injury, when animals were presumed to be insulin resistant (12), the mice were fasted overnight. The following morning, mice were injected with ${ }^{18} \mathrm{FDG}(50 \mu \mathrm{Ci})$ via the tail vein. Approximately $60 \mathrm{~min}$ after tracer injection, animals were sacrificed by cervical dislocation and complete biodistribution was measured as described above. The results were calculated as \% ID/g. All results were expressed as means \pm SEM. A sub-set burned and shamcontrol animals was injected with a larger dose of ${ }^{18} \mathrm{FDG}$ $(\sim 1.0 \mathrm{mCi})$ and tracer distribution was evaluated by $\mu$ PET.

$\mu$ PET imaging. To further evaluate the glucose metabolism in major organs, Positron Emission Tomography (PET) was

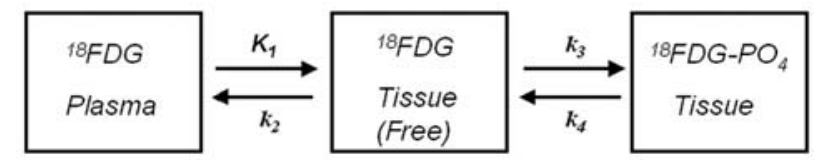

Figure 1. Kinetic model for ${ }^{18} \mathrm{FDG}-\mathrm{PET}$. When ${ }^{18} \mathrm{FDG}$ is injected, it is transported from plasma into cells according to the rate constant $\mathrm{K}_{1}$, transported back into plasma with the rate constant $\mathrm{k}_{2}$, phosphorylated with a rate constant $\mathrm{k}_{3}$ and dephosphorylated with a rate constant $\mathrm{k}_{4}$.

conducted in a sub-set of the animals described above; sham controls and burned mice with or without treatment with simvastatin at a dose of $0.2 \mu \mathrm{g} / \mathrm{kg}(\mathrm{n}=3 \mathrm{each})$. For these studies a larger dose of ${ }^{18} \mathrm{FDG}(\sim 1.0 \mathrm{mCi})$ was injected.

Imaging was performed with a Concord P4 micro-PET device. Primary imaging characteristics of the P4 camera are average intrinsic spatial resolution of 1.75 FWHM, 63 contiguous slices of $1.21 \mathrm{~mm}$ separation and a sensitivity of $1.43 \%$ for the $350-650 \mathrm{Kev}$ energy window (13).

${ }^{18} \mathrm{FDG}$ for measuring glucose metabolism, was injected $\sim 1 \mathrm{~h}$ before image acquisition. Acquisition was performed for $10 \mathrm{~min}$. The list mode data re-binned to a single sinogram and reconstructed using a filtered back projection (FBP) algorithm using a ramp filter with a cut-off of 0.5 . In all animals, the region from the head to the base of the tail was included in the $7.9 \mathrm{~cm}$ field of view of the camera. Data for attenuation correction was measured with a rotating point source containing ${ }^{57} \mathrm{Co}$. All projection data were corrected for non-uniformity of detector response, dead time, random coincidences, and scattered radiation. Regions of interest (ROIs) were drawn over selected tissues and activity was measured in $\mathrm{nCi} / \mathrm{ml}$.

When ${ }^{18} \mathrm{FDG}$ is injected, it is transported from plasma into cells according to the rate constant $\mathrm{K}_{1}$, transported back into plasma with the rate constant $\mathrm{k}_{2}$, phosphorylated with a rate constant $k_{3}$ and dephosphorylated with a rate constant $k_{4}$. Since, ${ }^{18} \mathrm{FDG}-\mathrm{PO}_{4}$ cannot proceed further in glycolysis or be used for glycogen synthesis, tracer accumulation reflects glucose utilization. The transport and metabolism of ${ }^{18} \mathrm{FDG}$ is summarized by the kinetic model in Fig. 1.

Oral glucose tolerance tests. These studies were performed on mice with burn injury, sham controls and burn-injured mice treated with simvastatin. On the day of the experiments, food was removed $10 \mathrm{~h}$ prior to administration of a $2 \mathrm{~g} / \mathrm{kg}$-glucose solution via gavage. Glucose levels were measured on serial whole blood samples acquired over $2 \mathrm{~h}$ with a Contour glucometer (Bayer Inc.). Areas under the plasma glucose curves (AUCs) were calculated using the trapazoidal rule.

Statistical analysis. Statistical analysis was performed by one or two-way analysis of variance (ANOVA). Individual means were compared by Duncan's multiple range test. Differences with a p-value of $<0.05$ were considered statistically significant.

\section{Results}

Fig. 2, illustrates the pattern of ${ }^{18} \mathrm{FDG}$ uptake in the brain and heart of sham-treated and burned mice at 24 and $168 \mathrm{~h}$ after injury. Two-way ANOVA demonstrated highly significant 


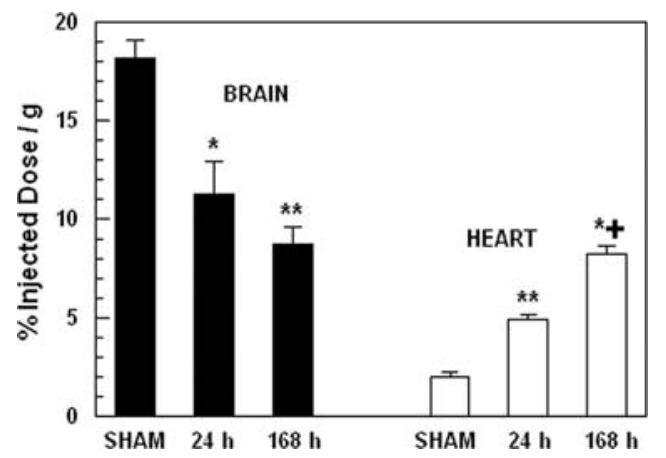

Figure 2. ${ }^{18} \mathrm{FDG}$ uptake in the brain and heart of sham-treated and burned mice at 24 and $168 \mathrm{~h}$ after injury. Each value is the mean \pm SEM for 6 animals " $\mathrm{p}<0.01$ vs. sham group, ${ }^{* *} \mathrm{p}<0.001$ vs. sham group, ${ }^{* * *} \mathrm{p}<0.001$ vs. sham and $24 \mathrm{~h}$ groups.

effects of treatment, $\mathrm{F}_{2,30}=110.49, \mathrm{p}<0.0001$ and tissue by treatment interaction, $\mathrm{F}_{2,35}=38.85, \mathrm{p}<0.0001$. In the brain, there was a monotonic decrease in tracer uptake over the time-course after injury. Tracer uptake was decreased by $38 \%$ compared with sham-treated control animals at $24 \mathrm{~h}$ after injury $(\mathrm{p}<0.01)$ and decreased further by $52 \%$ compared with sham-treated control animals at $168 \mathrm{~h}$ after injury $(\mathrm{p}<0.001)$. In contrast, cardiac uptake of ${ }^{18} \mathrm{FDG}$ demonstrated a monotonic increase over the time course after injury. Tracer uptake was increased by $246 \%$ compared with sham-treated control animals at $24 \mathrm{~h}$ after injury $(\mathrm{p}<0.001)$ and increased further by $315 \%$ compared with sham-treated control animals at $168 \mathrm{~h}$ after injury ( $<<0.001 \mathrm{vs}$. sham, $\mathrm{p}<0.001 \mathrm{vs.} 24 \mathrm{~h}$ ).

In addition to the tracer studies, observation of the behavior of the animals revealed signs consistent with cerebral dys-

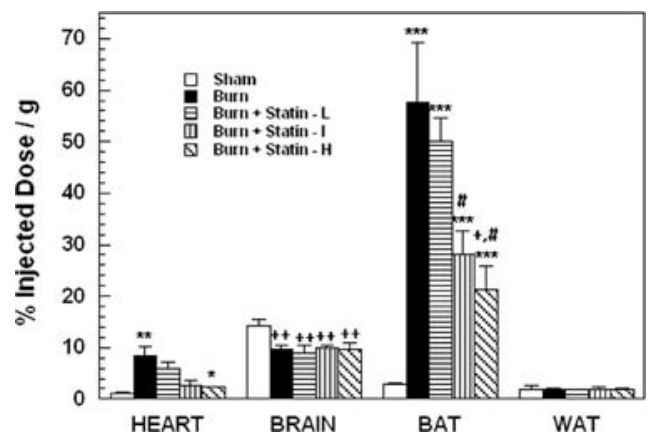

Figure $3 .{ }^{18}$ FDG uptake in brain, heart, BAT and WAT of burn injured mice, sham controls and burn injured mice treated with placebo or simvastatin at doses of 0.02 (Statin-L), 0.2 (Statin-I) and 2.0 (Statin-H) $\mu \mathrm{g} / \mathrm{g}$. Each value is the mean \pm SEM for 6 animals. Heart, ${ }^{* *} \mathrm{p}<0.01$ vs. sham; ${ }^{*} \mathrm{p}<0.05$ vs. burn alone; Brain, ${ }^{++} \mathrm{p}<0.01$ vs. sham; BAT, ${ }^{* * *} \mathrm{p}<0.001$ vs. sham, ${ }^{+} \mathrm{p}<0.05$ vs burn alone, ${ }^{\#} \mathrm{p}<0.05$ vs. simvastatin at $0.02 \mu \mathrm{g} / \mathrm{g}$.

function during the first $24 \mathrm{~h}$ after injury, including: lethargy, difficulty in righting after turning over, and disorientation in movement in the cage.

The pattern of ${ }^{18}$ FDG uptake in the brain, heart, BAT and WAT of mice treated with placebo and 3 doses of simvastatin at $24 \mathrm{~h}$ after burn injury and sham-treated controls is illustrated in Fig. 3. Two-way ANOVA demonstrated highly significant main effects of treatment, $\mathrm{F}_{4,100}=18.11 ; \mathrm{p}<0.0001$, tissue $\mathrm{F}_{3,100}=123.67, \mathrm{p}<0.0001$ and tissue by treatment interaction, $\mathrm{F}_{12,119}=15.57, \mathrm{p}<0.0001$. Burn injury produced significant increases in ${ }^{18} \mathrm{FDG}$ uptake by heart $(\mathrm{p}<0.01)$ and BAT $(\mathrm{p}<0.001)$ and a significant decrease in uptake by brain $(\mathrm{p}<0.01)$. In both heart and BAT, simvastatin treatment produced progressive and dose-dependent decreases in

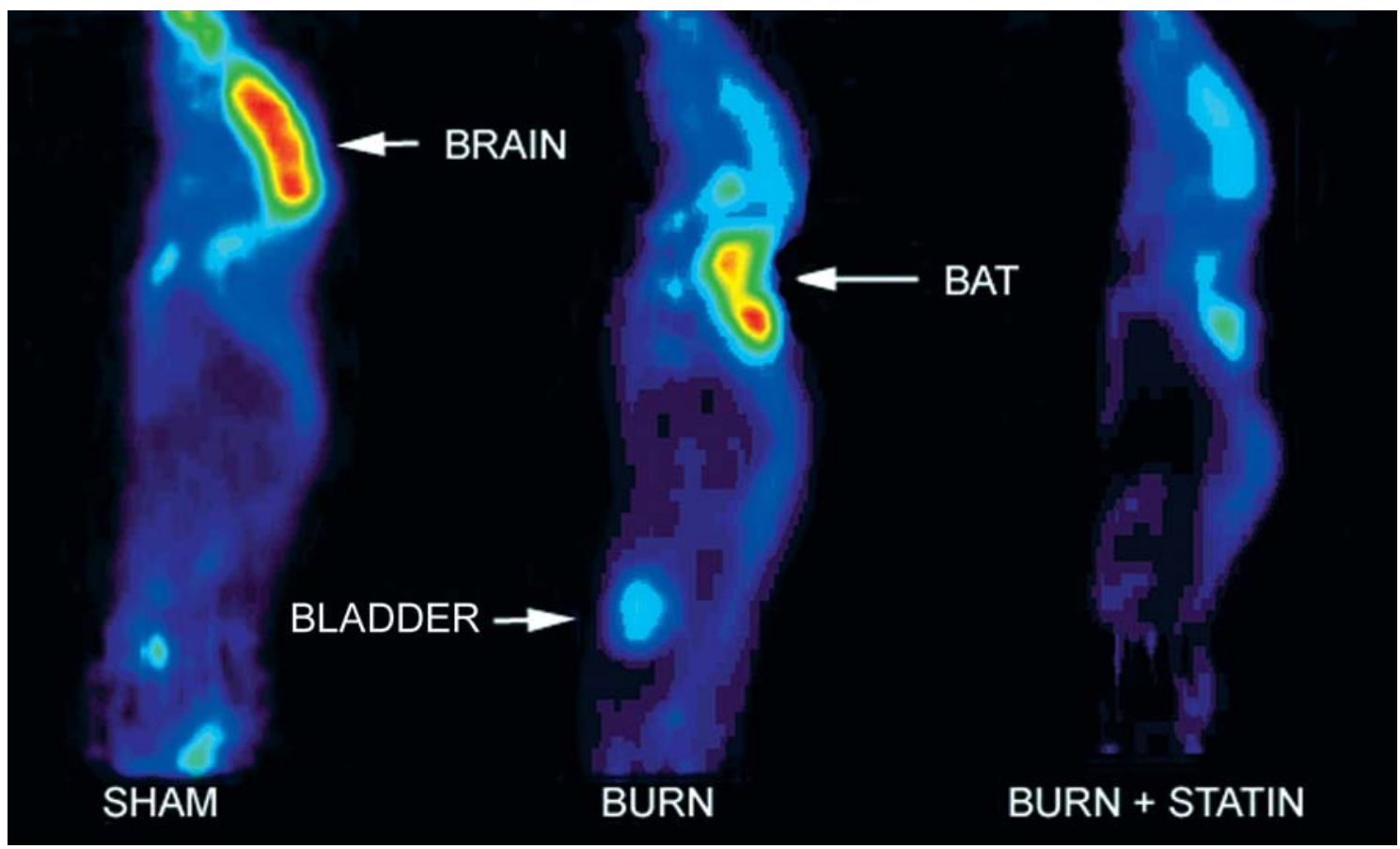

Figure 4. Representative ${ }^{18}$ FDG $\mu$ PET images of a sham control mouse, a mouse with burn injury and a burn injured mouse treated with simvastatin at a dose of $0.2 \mu \mathrm{g} / \mathrm{g}$. 


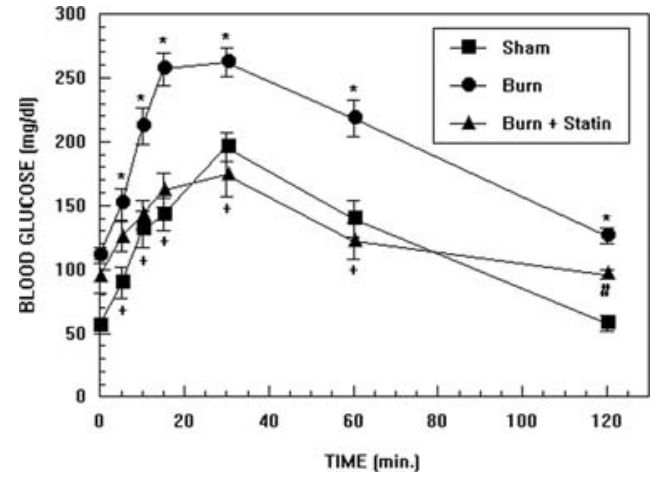

Figure 5. Oral glucose tolerance tests from burn-injured mice, sham controls and burn-injured mice treated with simvastatin at a dose of 0.02 and $0.2 \mu \mathrm{g} / \mathrm{g}$. Each value is the mean \pm SEM for 6 animals. ${ }^{*} \mathrm{p}<0.05$, burn vs. sham and burn vs. burn + statin; ${ }^{+} \mathrm{p}=\mathrm{NS}$, burn + statin vs sham; ${ }^{\#} \mathrm{p}<0.01$, burn + statin vs. sham.

tracer uptake. In BAT, uptake was significantly reduced by simvastatin at $0.2 \mu \mathrm{g} / \mathrm{g}$ compared to burn alone $(\mathrm{p}<0.05)$ and by simvastatin at 0.2 and $2 \mu \mathrm{g} / \mathrm{g}$ compared to simvastatin at $0.02 \mu \mathrm{g} / \mathrm{g}(\mathrm{p}<0.01)$. In contrast, tracer uptake in brain was not affected by simvastatin treatment. Burn injury with or without simvastatin had no effect on ${ }^{18}$ FDG uptake by WAT. Minor non-statistically significant effects of simvastatin treatment were detected in the other tissues that were sampled. There were no effects of simvastatin treatment on any tissues of sham-treated control animals (data not shown).

Fig. 4 illustrates representative ${ }^{18} \mathrm{FDG} \mu$ PET images of a sham control mouse (left), a mouse with burn injury (middle) and a burn injured mouse treated with simvastatin at a dose of $0.2 \mu \mathrm{g} / \mathrm{g}$ (right). After injury there was intense tracer uptake in BAT that was associated with significant reductions in uptake by all other tissues, including the brain. After treatment with simvastatin, ${ }^{18} \mathrm{FDG}$ uptake in BAT returned toward the level observed in sham-treated mice and uptake in the brain was partially normalized (Fig. 3). Similar results were observed in all animals that were studied.

The results of oral glucose tolerance tests performed in burn-injured mice, sham controls and burn-injured mice treated with simvastatin at a dose of $0.2 \mu \mathrm{g} / \mathrm{g}$ are illustrated in Fig. 5 . Two-way ANOVA demonstrated highly significant effects of treatment, $\mathrm{F}_{2,168}=56.33 ; \mathrm{p}<0.0001$, time $\mathrm{F}_{6,168}=33.39 ; \mathrm{p}<0.0001$ and treatment by time interaction, $\mathrm{F}_{12,188}=1.89 ; \mathrm{p}<0.05$. At the first time point, blood glucose levels were higher in burned mice compared with sham-treated controls $(\mathrm{p}<0.005)$ but levels in the burn and burn + simvastatin groups were not significantly different. At $5 \mathrm{~min}$, glucose levels increased in all 3 groups of mice (burned vs. sham; $p<0.02$, burned vs. burned + simvastatin and burned + simvastatin vs. sham; $\mathrm{p}=\mathrm{NS}$ ). At $10 \mathrm{~min}$, glucose levels increased further in all 3 groups (burned vs. sham, $\mathrm{p}<0.02$; burned vs. burned + simvastatin, $\mathrm{p}<0.02$; burned + simvastatin vs. sham, $\mathrm{p}=\mathrm{NS}$ ). At 15 min there was a further increase in glucose levels (burned vs. sham, $\mathrm{p}<0.005$; burned vs. burned + simvastatin, $\mathrm{p}<0.02$; burned + simvastatin vs. sham, $\mathrm{p}=\mathrm{NS}$ ). At $30 \mathrm{~min}$ there was a slightly further increase in glucose levels (burned vs. sham, $\mathrm{p}<0.05$; burned vs. burned + simvastatin, $\mathrm{p}<0.02$; burned + simvastatin vs. sham, $\mathrm{p}=\mathrm{NS}$ ). Peak glucose levels appeared to be achieved in all groups of mice between 15 and

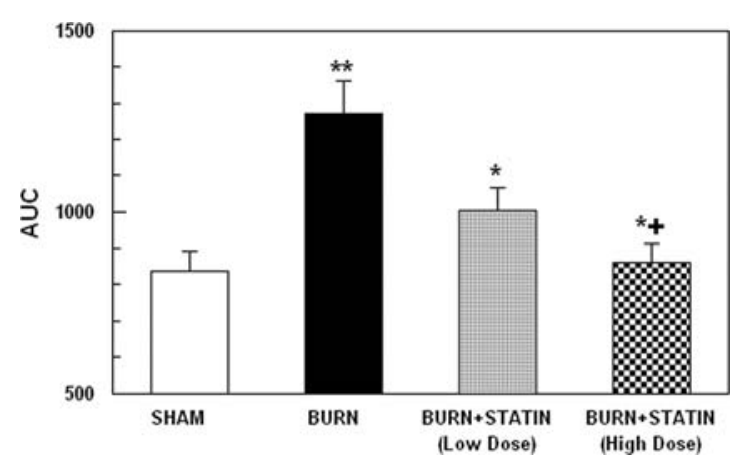

Figure 6: Glucose AUCs from oral glucose tolerance tests in burn injured mice, sham controls and burn injured mice treated with simvastatin at a doses of $0.2 \mu \mathrm{g} / \mathrm{g}$. Each value is the mean \pm SEM for 6 animals. ${ }^{*} \mathrm{p}<0.01$ vs. burn group, ${ }^{* *} \mathrm{p}<0.001 \mathrm{vs}$. sham group; ${ }^{+} \mathrm{p}=\mathrm{NS}$ vs. sham group.

$30 \mathrm{~min}$. At $60 \mathrm{~min}$ glucose levels decreased in all groups (burned vs. sham; $\mathrm{p}<0.05$, burned vs. burned + simvastatin; $\mathrm{p}<0.02$, burned + simvastatin vs. sham; $\mathrm{p}=\mathrm{NS}$ ). At the final time of measurement, glucose levels continued to decrease and the differences among all groups was statistically significant; most probably due to the low variance of the measurements at this time point (burned vs. sham, $\mathrm{p}<0.005$; burned vs. burned + simvastatin, $\mathrm{p}<0.02$; burned + simvastatin vs. sham, $\mathrm{p}<0.005)$.

An additional group of 5 mice with burn injury that were studied with a lower dose of simvastatin $(0.02 \mu \mathrm{g} / \mathrm{kg})$ yielded a similar but less pronounced effect. For the purpose of clarity, these results were not included in Fig. 5.

AUCs for the curves in Fig. 5, including the results of the low-dose simvastatin study, are illustrated in Fig. 6. One-way ANOVA revealed a highly significant main effect of treatment, $\mathrm{F}_{3,36}=8.10 ; \mathrm{p}<0.0005$. These data indicate that the AUC for the burned mice was significantly higher than for the sham controls $(\mathrm{p}<0.005)$ and the AUC for the burn + higher dose simvastatin group was significantly lower than the burn group $(\mathrm{p}<0.01)$. The AUC for the burn + lower dose simvastatin group tended to show a modest reduction compared to the burn group, however, the difference was not statistically significant $(p=0.12)$. The AUCs for both simvastatin groups were not significantly different from the sham controls or each other.

\section{Discussion}

Statins were originally designed to inhibit production of cholesterol by the liver. However, subsequent to their introduction into clinical practice several additional actions have been identified. For example, statins have been shown to have a protective effect in patients with severe sepsis, as demonstrated by a significant reduction in mortality compared with patients not receiving statins (7) and in burned mice subjected to cecal ligation and puncture (9).

The present study clearly demonstrated the effects of statins in reducing burn injury induced alterations in glucose metabolism by brain, heart and BAT and their effect on improving glucose tolerance. It is not immediately clear why statins should also be involved in the correction of burn induced insulin resistance as evidenced by changes we 
observed in oral glucose tolerance tests, or the reduction in burn-induced stimulation of ${ }^{18} \mathrm{FDG}$ uptake by heart and BAT.

Severely burned and other critically ill patients exhibit insulin resistance which complicates their management. We have demonstrated that burn injury produces insulin resistance in mice (11), rats (12) and rabbits (unpublished data). These studies have demonstrated that hepatic production of glucose becomes resistant to insulin induced reduction in glucose production. Hence, one possible mechanism for statin mediated correction of burn induced insulin resistance may be related to alterations in hepatic glucose production after injury. We have also demonstrated that burn injury to mice results in increased phosphorylation of IRS-1 at serine residues, which would contribute, in part to the burn induced insulin resistance (11).

The effect of statins in ameliorating insulin resistance in numerous other pathophysiological conditions have been reported in previous studies of human subjects and animals.

Guclu et al (14) studied the effects of pravastatin on insulin resistance in patients with metabolic syndrome and impaired glucose tolerance (IGT), using the Homeostasis Model Assessment (HOMA) test, insulin sensitivity indices and glucose half activation time (glucose $\mathrm{t}_{1 / 2}$ ). The study population consisted of 25 women who were diagnosed with metabolic syndrome. At baseline and 10 weeks after daily oral treatment with pravastatin (20 mg/day), waist/hip circumference, body weight, arterial blood pressure, plasma glucose, total cholesterol, triglyceride, high density lipoprotein (HDL)cholesterol, transaminases, glycosylated hemoglobin (A1C) and insulin levels were measured and HOMA and insulin tolerance testing was performed after $12 \mathrm{~h}$ of fasting. After treatment with pravastatin, there were significant decreases in arterial blood pressure and baseline insulin levels. In contrast, there was an increase in insulin sensitivity and a decrease in glucose $t_{1 / 2}$. Related to the improvement in these parameters, statistically significant decreases were also observed in HOMA, postprandial and fasting glucose levels and A1C values $(\mathrm{P}<0.0001)$. These authors concluded that pravastatin treatment may be an effective approach for treating insulin resistance.

Lalli et al (15) examined the effect of lovastatin on insulin sensitivity and signaling in the liver and muscle of rats maintained on a high-fat diet (HFD) for 4 weeks. Their results indicated that lovastatin treatment resulted in a marked improvement in insulin sensitivity characterized by an increase in glucose disappearance rate during insulin tolerance tests. This increase in insulin sensitivity was associated with an increase in insulin-induced insulin receptor (IR) tyrosine phosphorylation and a parallel decrease in IR serine phosphorylation and association with PTP1B. They also demonstrated that lovastatin treatment was associated with an increase in insulin-stimulated insulin receptor substrate (IRS) phosphatidylinositol 3-kinase/Akt pathway in the liver and muscle of HFD-fed rats in parallel with a decrease in the inflammatory pathway (c-jun $\mathrm{N}$-terminal kinase and Iкß kinase $(\mathrm{IKK} ß) / \mathrm{I} \kappa \mathrm{B} / \mathrm{NF}-\kappa \mathrm{B})$ related to insulin resistance.

In another investigation, Naples et al (16) studied the effect of rosuvastatin treatment of insulin resistant hamsters to determine if this treatment can induce improvements in hepatic and whole body insulin sensitivity. Treatment with rosuvastatin at $10 \mathrm{mg} / \mathrm{kg} /$ day for 10 days significantly reduced fasting insulin $(-59 \%)$ and triglyceride $(-50 \%)$ levels in fructose-fed hamsters $(\mathrm{p}<0.05)$. Following an intraperitoneal (i.p.) glucose challenge, rosuvastatin-treated hamsters exhibited enhanced glucose clearance compared to untreated hamsters maintained on the high-fructose diet [area under curve $(\mathrm{AUC})=1,772 \pm 223$ vs. $2,413 \pm 253 \mathrm{mM}$ min, respectively; $\mathrm{p}<0.002]$ with a significant reduction in $2 \mathrm{~h}$ post-challenge glucose $(\mathrm{n}=5$, $\mathrm{p}<0.02$ ). Rosuvastatin-treatment also significantly improved sensitivity to an i.p. insulin challenge $(\mathrm{AUC}=314 \pm 39$ vs. $195 \pm 22 \mathrm{mM}$ min for rosuvastatin-treated and fructose-fed hamsters, respectively; $\mathrm{p}<0.04, \mathrm{n}=3$ ). At the molecular level, significant increases in tyrosine-phosphorylation of the hepatic insulin receptor and IRS-1 were observed for rosuvastatintreated hamsters $(+37$ and $+58 \%$, respectively) compared to fructose-fed controls following an intravenous (i.v.) bolus of insulin $(\mathrm{p}<0.05)$. Increases in IR and IRS-1 phosphorylation were also observed in muscle and adipose tissue. Analysis of hepatic Akt phosphorylation and mass revealed a small (25\%) increase in serine phosphorylation of Akt with no significant change in Akt mass, although serine-phosphorylation and mass of Akt 2 were significantly increased $(+32 \%, \mathrm{p}=0.03$, and $+42 \%, \mathrm{p}=0.01$, respectively). Interestingly, expression of PTP-1B, a key negative regulator of insulin signaling, showed a non-significant trend toward reduction in liver and was significantly reduced in adipose tissue (-20 and $-37 \%$, respectively). The authors suggested that statin-treatment increases whole body and peripheral tissue insulin sensitivity via improved cellular insulin signal transduction.

Abe et al (17) demonstrated that pravastatin did not increase plasma adiponectin levels although normal mice treated with pravastin did show such an increase. Adiponectin is an insulin sensitizing factor derived from adipocytes. When obese mice were treated with pravastitin, the increase in mRNA expression of proinflammatory genes, including MCP1 and IL-6 in adipose tissue was attenuated. It was pointed out that macrophages accumulate in adipose tissue with increased body weight and the levels of these cells correlated with measures of insulin resistance. Since macrophages in adipose tissue are the major source of proinflammatory cytokines, there may be a link between inflammation and insulin resistance, at least in obese mice. The authors suggested that it may be the anti-inflammatory effect of statin treatment that helps reduce insulin resistance in this model.

Inflammatory activity in fat tissue has recently been implicated in the mechanism(s) of insulin resistance and obesity-related metabolic dysfunction. In a recent study, Vitseva et al (18) biopsied abnormal subcutaneous abdominal fat from 16 obese subjects (age 39 111 years, BMI $49 \pm 14 \mathrm{~kg} / \mathrm{m}^{2}$ ) and studied Toll-like receptors (TLRs) which are know to play a key role in innate immune responses and are involved in the mechanisms of inflammation. Their findings demonstrated that TLRs are inducible in adipose tissue and are linked with downstream NF- $\mathrm{B}$ activation and cytokine release. They also suggested that adipose stores play a dynamic role in the regulation of inflammation and innate immunity in human subjects via modulation of the TLR/NF-kB regulatory pathway.

In vitro studies have demonstrated that statins are able to decrease the activation of $\mathrm{NF}-\kappa \mathrm{B}$ by increasing the expression of the NF- $\mathrm{NB}$ inhibitory protein $\mathrm{I} \kappa \mathrm{B}$, resulting in reduced 
cytokine production (19) and therefore, for example, reduced iNOS expression and iNOS-mediated NO production (20). Very recently we observed that burn injury to mice leads to activation of $\mathrm{NF}-\mathrm{KB}$ transcription in BAT in two different transgenic models (unpublished data). In this study, statin treatment reduced burn-induced stimulation of $\mathrm{NF}-\kappa \mathrm{B}$ activation in BAT, as measured by luciferase activity. Whether the reduction in burn-induced changes in glucose tolerance and $\mathrm{NF}-\kappa \mathrm{B}$ expression produced by statin treatment are related to a suppression of inflammation by statin was not determined. Clearly, these issues require further investigation.

\section{Acknowledgements}

This study was supported in part by grants from the National Institutes of Health (2P50 GM21700-27A) and Shriners Hospitals for Children (\#8540).

\section{References}

1. Carter E, Tompkins RG, Babich JW and Fischman AJ: Effect of thermal injury on uptake and phosphorylation of F-18 flurodeoxyglucose. J Nucl Med 34: P175, 1994.

2. Carter EA, Tompkins RG, Babich JW, Correia JA and Fischman AJ: Effects of thermal injury and modifiers of energy metabolism on FDG utilization by rat brain. J Nucl Med 36: P205, 1995.

3. Carter EA, Tompkins RG, Babich JW, Correia J and Fischman AJ: Decreased cerebral glucose utilization in rats during the ebb phase of thermal injury. J Trauma 40: 930-935, 1996.

4. Zhang Q, Carter EA, Ma B, Fischman AJ and Tompkins RG: Burn-related metabolic and signaling changes in rat brain. J Burn Care Res 29: 346-352, 2008.

5. Carter EA, Winter D, Tolman C, Tompkins RG and Fischman AJ: Burn induced changes in cerebral and myocardial glucose metabolism in rodents. J Nucl Med 50: P1216, 2009.

6. Chaudry MZ, Want JH, Blankson S and Redmond HP: Statin (cerivastatin) protects mice against sepsis-related death via reduced proinflammatory cytokines and enhanced bacterial clearance. Surg Infect 9: 183-194, 2008.

7. Dobesh PP, Klepser DG, McGuire TR, Morgan CW, Olsen KM: Reduction in mortality associated with statin therapy in patients with severe sepsis. Pharmacotherapy 29: 621-630, 2009.

8. Fogerty MD, Abumrad N, Efron D, Guy J and Barbul A: The effect of preinjury statin use on mortality and sepsis in elderly burn patients. J Trauma (In press).
9. Beffa DC, Carter EA, Hamrahi VF, Yu YM, Fagan S, Sheridan RL, Fischman AJ and Tompkins RG: Simvastatin improves survival in murine gram negative burn sepsis. J Burn Care Res 28: S85, 2007.

10. Shinozaki S, Inoue Y, Yang W, Fukaya M, Carter EA, Yu YM, Fischman AJ, Tompkins RG and Kaneki M: Farnesyltransferase inhibitor improved survival following endotoxin challenge in mice. Biochem Biophys Res Commun 391: 1459-1464, 2010.

11. Zhang Q, Carter EA, Ma BY, White M, Fischman AJ and Tompkins RG: Molecular mechanism(s) of burn induced insulin resistance in murine skeletal muscle: role of IRS phosphorylation. Life Science 77: 3068-3077, 2005.

12. Carter EA, Burks D, Fischman AJ, White M and Tompkins RG: Insulin resistance in thermally injured rats is associated with post-receptor alterations in skeletal muscle, liver and adipose tissue. Int J Mol Med 14: 653-658, 2004.

13. Tai C, Chatziioannou A, Siegel S, Young J, Newport D, Goble RN, Nutt RE and Cherry SR: Performance evaluation of the microPET P4: a PET system dedicated to animal imaging. Phys Med Biol 46: 1845-1862, 2001.

14. Guclu F, Ozmen B, Hekimsoy Z and Kirmaz C: Effects of a statin group drug, pravastatin, on the insulin resistance in patients with metabolic syndrome. Biomed Pharmacother 58: 614-618, 2004.

15. Lalli CA, Pauli JR, Prada PO, Cintra DE, Ropelle ER, Velloso LA and Saad MJ: Statin modulates insulin signaling and insulin resistance in liver and muscle of rats fed a high-fat diet. Metabolism 57: 57-65, 2009.

16. Naples M, Federico LM, Xu E, Nelken J and Adeli K: Effect of rosuvastatin on insulin sensitivity in an animal model of insulin resistance: evidence for statin-induced hepatic insulin sensitization. Atherosclerosis 198: 94-103, 2008.

17. Abe M, Matsuda M, Kobayashi H, Miyata Y, Nakayama Y, Komuro R, Fukuhara A and Shimomura I: Effects of statins on adipose tissue inflammation: their inhibitory effect on MyD88independent IRF3/IFN- $\beta$ pathway in macrophages. Atherioscler Thromb Vasc Biol 28: 871-877, 2008.

18. Vitseva OI, Tanriverdi K, Tchkonia TT, Kirkland JL, McDonnell, ME Apovian CM, Freedman J and Gokce N: Inducible toll-like receptor and NF-?B regulatory pathway expression in human adipose tissue. Obesity 16: 932-937, 2008.

19. Zelvyte I, Dominaitiene R, Crisby M and Janciauskiene S: Modulation of inflammatory mediators and PPAR gamma and NF kappa B expression by pravastatin in response to lipoproteins in human monocytes in vitro. Pharmacol Res 45: 147$154,2002$.

20. Giusti-Paiva A, Martinez MR, Felix JV, da Rocha MJ, Carnio EC, Elias LL and Antunes-Rodrigues J: Simvastatin decreases nitric oxide overproduction and reverts the impaired vascular responsiveness induced by endotoxic shock in rats. Shock 21: 271-275, 2004. 